\title{
OS CAMINHOS DE RESISTÊNCIA E POTENCIALIZAÇÃO DOS DIREITOS
} HUMANOS E DESENVOVLIMENTO SOCIOAMBIENTAL

José Boeing ${ }^{*}$

\begin{abstract}
Resumo: Os caminhos de resistência e potencialização dos Direitos Humanos e sustentabilidade vivem o drama da mudança de época. O Desenvolvimento visto como crescimento econômico aumentou a renda dos capitalistas, excluindo os pobres. Por outro lado, o povo exige justiça social. A Declaração Universal dos Direitos Humanos, garante a dignidade humana. Por isso, as organizações populares lutam para garantir esses Direitos. Esta luta tem trazido consequências com o martírio de inúmeros defensores dos Direitos Humanos. Amazônia, apresenta caminhos de resistência e de justiça restaurativa com mediação dos conflitos socioambientais na construção de um projeto de sociedade.
\end{abstract}

Palavras-chave: Direitos Humanos; Resistência; Justiça Social; Sustentabilidade; Movimentos Sociais.

\section{INTRODUÇÃO}

Para os seres humanos não pode haver coisa mais valiosa do que o respeito aos direitos da dignidade da pessoa humana. Pessoa que, por suas características naturais é dotada de inteligência, consciência e vontade, por ser mais do que uma simples porção de matéria, tem uma dignidade que a coloca acima de todas as coisas da natureza, embora não está desconectado do meio ambiente, pois faz parte do todo. Mesmo as teorias chamadas materialistas, que não querem aceitar a espiritualidade da pessoa humana, sempre foram forçadas a reconhecer que existe em todos os seres humanos uma parte não material. Existe

\footnotetext{
* Mestre em Direito Ambiental e Desenvolvimento Sustentável da Escola Superior Dom Helder Câmara ESDHC. Doutor em Direito pela Universidad Nacional Mar del Plata, Argentina. Graduado em Filosofia PUC/PR. Bacharel em Teologia pelo ITESP/SP. Graduado em Direito pela FIT/PA. Pós Graduação em Ciências da Religião pelo IESPES/PA. Advogado membro da CPT no Pará e Religioso dos Missionários do Verbo Divino na Amazônia.
} 
uma dignidade inerente à condição humana, e a preservação dessa dignidade faz parte dos direitos humanos.

O respeito pela dignidade da pessoa humana deve existir sempre, em todos os lugares e de maneira igual para todos. O crescimento econômico e o progresso material de um povo têm valor negativo se forem conseguidos à custa do desrespeito aos direitos humanos. $\mathrm{O}$ sucesso político ou militar de uma pessoa ou de um povo, bem como o prestígio social ou a conquista de riquezas, nada disso é válido ou merecedor de respeito se for conseguido mediante ofensas à dignidade e aos direitos fundamentais dos seres humanos.

O estudo sobre os caminhos de resistência e potencialização dos direitos humanos e meio ambiente na Amazônia, se fortalece por buscar um projeto de sociedade que contempla a vida e a justiça. Para efetivar essa compreensão serão aprofundados os pontos da ordem econômica, social, política, cultural e religiosa. Diante disso, iremos apresentaremos alternativas possíveis de Justiça Social, direitos humanos e meio ambiente.

Desde a Declaração Universal dos Direitos Humanos pela ONU em 1948, tem sido debatido e aprofundado este tema como necessidade de que em cada país a efetivação, respeito, proteção e promoção dos Direitos Humanos individuais, sociais e ambientais como projeto de sociedade. No entanto, a população, através de suas organizações sociais exigem, através das políticas públicas a dignidade da pessoa humana.

Esta realidade da violação dos Direitos Humanos, Econômicos, Sociais, Culturais e Ambientais - DHESCA, conforme a ONU constata, exige do Brasil, política efetiva, principalmente na Amazônia, colocando em prática o PNDH - Plano Nacional dos Direitos Humanos. Cada cidadão deve lutar em defesa dos Direitos Humanos e Sustentabilidade como projeto de sociedade, garantindo a ética e justiça social para as presentes e futuras gerações. 


\section{A ORDEM ECONÔMICA MUNIDAL E A EXCLUSÃO SOCIAL}

$\mathrm{Na}$ atualidade verifica-se que o neoliberalismo se afirmou como um esquema ortodoxo de dimensões sem precedentes históricos, em virtude da sua amplitude e da sua força a nível mundial. Na "nova ordem mundial", existe uma única base sobre a qual se discutem os problemas do mundo: a economia neoclássica. Proclama-se, praticamente como um dogma que há um só caminho de "salvação" para todos os povos, sejam quais forem as suas tradições, valores, história ou costumes, sejam do Norte ou do Sul - e esse caminho chama-se mercado. A economia é a linguagem humana dominante nestes tempos e ela determina a vida coletiva do planeta. Todos os mercados financeiros do mundo estão interligados mediante um único sistema computadorizado. Esta nova "realidade" está transformando a face da comunidade internacional e está criando cada vez mais pobreza e destruição do meio ambiente.

Embora a globalização da economia se apresente sob formas diversas consoantes com o país em que se vive, ela influencia, cada vez mais diretamente, a vida quotidiana. Constatase o custo de vida elevado: enquanto se idolatra a economia do mercado mundial, quatro pessoas em cada cinco não têm poder aquisitivo; fome: um quinto da população mundial padece de fome e três milhões de crianças morrem de desnutrição todos os anos. As crianças e outros grupos vulneráveis e desfavorecidos, tais como as populações indígenas, quilombolas e comunidades tradicionais que são necessitados dos direitos humanos individuais e sociais ${ }^{1}$. Neste sentido, Felix Wilfred, ao analisar a Globalização e o compromisso dos cristãos em defesa dos pobres, é categórico ao afirmar que:

Nenhum cristão pode ser defensor tácito dum sistema que marginaliza os pobres. Digo "defensor tácito" porque a falta da nossa tomada de posição equivale a uma defesa. Hoje em dia, devemos dar-nos conta de que a opção a favor dos pobres também significa, necessariamente, uma opção contra um sistema econômico que continua a fazer um crescente número de vítimas. A fé não pode comunicar a vida se não tiver nada para dizer sobre os elementos primordiais que designamos por alimento, água, terra, casa, segurança (WILDRED, 1996, N. 305).

\footnotetext{
${ }^{1}$ O Movimento Mundial das Operários Cristãos lançou um Plano de Quatro Anos (1996-2000) para promover a dignidade humana, reanimando a esperança das pessoas e criar novas formas de solidariedade. Este plano foi incluído no seu Boletim "INFO", n. 154, Julho-Agosto de 1996.
} 
Esse modelo econômico, justificado sob a "liberdade" é pensado para poucos. Neste sentido, João Batista Moreira Pinto e Alexandre Bernardino Costa, publicam o artigo sobre o Projeto dos direitos Humanos. Eles analisam a situação de exclusão no sistema Neoliberal:

\begin{abstract}
O que vivenciamos, hoje, na sociedade global e na grande maioria dos Estados-nação, após a implantação em âmbito mundial de instituições e estruturas neoliberais dominantes que levaram as sociedades a serem parte de um mercado mundial aberto, é uma maior concentração da riqueza, com consequente manutenção, se não intensificação da desigualdade social nos Estados e pelo mundo, levando à exclusão de parte significativa da população quanto às possibilidades de vida efetiva, tanto em termos individuais como sociais e políticos (PINTO; COSTA, 2013).
\end{abstract}

A exclusão torna-se evidente e visível, pois para os defensores do modelo neoliberal, se muitos países pobres desaparecessem, não fariam diferença ao mercado. Essa arrogância do modelo que exclui deve ser barrada a partir de alternativas de Justiça Social ${ }^{2}$.

\title{
3. A ORDEM POÍTICA MUNDIAL E JUSTIÇA SOCIAL
}

Para exercitar novos valores e premissas da nova "mundialidade", o movimento antiglobalização neoliberal, começa a reclamar, implícita ou explicitamente, uma nova reformulação dos marcos de ação universal. A viabilidade do "outro mundo possível" começou a ser plasmada na recuperação da auto confiança do movimento social. Em sua capacidade de convergência e de calendários cênicos de consenso, que fazem da ação uma comunicação libertadora (MOREIRA, 2006, p. 156).

A questão da política pública é bem complexa, pois deveria ser garantida pelo Estado e pelas diferentes instituições que atuam dentro dele. O que se constata é que há grandes áreas, tanto urbanas como rurais, em que não é o Estado quem normatiza e define os princípios de organização e convivência social. As regras nestes espaços não seguem a legislação estabelecida no âmbito nacional, segue sim, as impostas pelos que controlam o poder global e local.

A justiça pelo reconhecimento e respeito à igualdade de cada pessoa e de cada cultura, resultará do trabalho contínuo para arrancar os preconceitos pela raiz. O programa político de cada país sofre sempre a influência dos "centros do poder mundial". O mundo

\footnotetext{
${ }^{2}$ Ver este tema o artigo de José Boeing sobre o poder do Estado e a Construção da Justiça e Paz. São Paulo: Paulus. Vida Pastoral mar-abril de 2009, pp. 21-27. Disponível em: http://vidapastoral.com.br/artigos/atualidade/o-poder-do-estado-e-a-construcao-da-justica-e. Acesso em 19 nov. 2014.
} 
como um todo sofre a imposição de um mesmo modelo de democracia, igual para todos. A nível político, prevalece a exclusão dos cidadãos, com base na discriminação étnica, religiosa. Tanto os países capitalistas como os comunistas são responsáveis por terem desenvolvido um aparelho burocrático que não dá a verdadeira liberdade aos cidadãos. Alguns países ainda continuam a praticar a tortura, por razões políticas.

Segundo a filósofa Marilena Chauí, a violência é a realização determinada pela força entre pessoas ou classes. Em vez de ser violência de transgressão ou norma, é relação de PODER. Isto é, conversão de uma diferença e de uma assimetria numa relação hierárquica de desigualdade com fins de dominação, de exploração e agressão, fortalecendo os privilegiados do sistema capitalista (CHAUÍ, 1980). Por isso, é preciso ter consciência das suas causas e expressões. Ora, isto leva-nos a perguntar: quais são os diversos tipos de "forças" de poder que operam neste mundo? Segundo Thomas Merton há muitos fatores de violência, pois:

\begin{abstract}
O verdadeiro problema moral da violência no século vinte está obscurecido por pressupostos arcaicos e míticos. Nós tendemos a calcular a violência em termos do que é individual, confuso, fisicamente perturbador e pessoalmente aterrador... Isso é razoável, mas tende a influenciar-nos demais. Leva-nos a pensar que o problema da violência se limita a esta muito pequena escala, e torna-nos incapazes de apreciar o problema muito maior da presença mais abstrata, mais global e mais organizada da violência em nível das massas e dos grupos. A violência de hoje é uma violência de "colarinho branco", a da destruição sistematicamente organizada, burocrática e tecnológica do homem (TERRY; DENNIS, 2012, pp.164-172).
\end{abstract}

Há uma forte tendência para limitar a compreensão da violência ao que é físico e individual. Esquecemos de observar que às formas organizadas, burocráticas e sistêmicas de violência são responsáveis pela atual cultura da morte. A violência manifesta-se nas formas de maus tratos aos pobres e aos marginalizados, às mulheres e às crianças, aos idosos e às pessoas com deficiências (TERRY; DENNIS, 2012, pp.172). O contraste é tão grande que se percebe na história a desigualdade, como escreve Bertrand de Jouvenel:

A desigualdade de fato constitui o principal tema dos séculos XIX e XX. Sem dúvida, não se trata de um tema novo: a novidade consiste no fato de se ter transformado progressivamente no tema dominante. Não estaríamos cometendo um grande exagero se disséssemos que a maior parte dos trabalhos importantes desses dois séculos poderia trazer um título comum: "Das causas das Desigualdades de Fato e dos Remédios próprios para aboli-las ou atenuá-las" (JOUVENEL, 2013, p.172). 
Começamos a construir a justiça social, pela mudança do coração da pessoa humana, ou pela mudança das estruturas sociais? Se o homem novo, da sociedade ideal, começa a ser edificado com justiça social por dentro ou por fora? Observando o caminhar da história, podemos buscar aprofundar a temática na compreensão do comportamento do ser humano diante deste modelo de exclusão mundial da dignidade da pessoa humana. O Papa João Paulo II, em sua visita ao Brasil, na homilia pronunciada em Belo Horizonte, em 10 de Julho de 1980, afirmou:

A Justiça Social só é verdadeira se baseada nos direitos do indivíduo. É que esses direitos só serão reconhecidos se for reconhecida a dimensão fundamental do homem, criado à imagem e semelhança de Deus, e destinado a uma vida eterna. Negar essa transcendência é reduzir o homem a instrumento de domínio, cuja corte está sujeita ao egoísmo e ambição de outros homens, ou onipotência do Estado totalitário, erigido em valor supremo. Não se constrói urna sociedade que mereça o título de humana, desrespeitando e, pior ainda, destruindo a liberdade humana, negando aos indivíduos as liberdades mais fundamentais. Não se constrói uma sociedade justa sobre a injustiça (PICANÇO, 1982, p. 7).

A Justiça Social é um fim procurado pelo ser humano para atender os seus princípios morais, culturais e espirituais. A questão que deve ser colocada é a ideia dos Direitos Humanos e a de Justiça Social. Trata-se de uma justiça que pretende debruçar-se sobre o lado especificamente social do viver humano, e, portanto sobre deveres sociais, posto que a justiça supõe sempre uma ética e toda ética projeta uma teoria dos deveres. Trata-se de relacionar essa justiça com uns tantos direitos que por motivos históricos se denominam especificamente de humanos (SALDANHA, 1982, p. 11-13). E no Brasil, a maioria do povo e da produção nacional no mercado informal, que são os negros, os índios, os ciganos, os catadores de papel, os sem-terra, sem- teto e os desempregados (LENZI, 1982, p. 14-17). Como exigir do Estado as garantias constitucionais, respeitando os direitos humanos?

A intervenção do Estado deve ser capaz de prevenir e proteger a sociedade e os cidadãos da violência e da criminalidade, por exemplo. A questão da segurança pública é um direito de todos. O novo sujeito da gestão de políticas de segurança pública tem de ocupar uma posição estratégica nos diversos níveis de governo. A sociedade civil deve ser convocada para uma mobilização nacional pela construção social da paz. O diálogo com as sociedades locais, devem criar condições para negociação democrática dos contratos de co-gestão, 
envolvendo o compartilhamento de responsabilidades na elaboração do diagnóstico, seleção das prioridades, identificação das metas e avaliação dos resultados.

O Estado deve garantir e afirmar que o cidadão é o destinatário dos serviços das políticas públicas e garantir um plano nacional de Segurança Pública ${ }^{3}$. Isso significa reconhecer a necessidade de promover uma superação de uma cultura de guerra para uma cultura de paz. As ações policiais devem passar a respeitar as diferenças de gênero, classe, idade, pensamento, crenças, etnia e orientação sexual, criando instâncias de proteção aos direitos dos diferentes. Infelizmente, grande parte dos conflitos vem do processo de criminalização dos movimentos sociais e pessoas defensoras dos direitos humanos. Não aceitam que a sociedade organizada contribua para combater as desigualdades sociais.

Os principais instrumentos de mudança das políticas públicas estão ligados à educação, à ética e aos Direitos Humanos. Assim poderá implementar políticas integradas que focalizem os três domínios fundamentais para a vida social: a casa, a rua - ou a comunidade e o bairro - e a escola, inclusive seu desdobramento profissionalizante, que conduz ao trabalho.

\section{PROGRMA NACIONAL dos direitos humanos E A PROTEÇÃo AOS DEFENSORES E DEFENSORAS DE DIREITOS HUMANOS}

No ano de 1948, a Organização das Nações Unidas - ONU, aprovou a Declaração Universal dos Direitos Humanos, que diz no $1^{\circ}$ Artigo, que "todos os seres humanos nascem livres e iguais em dignidade e direito" (BORGES, 2003, p.6) ${ }^{4}$. Além disso, segundo a Declaração, todos devem agir, em relação uns aos outros, "como espírito de fraternidade". A pessoa consciente do que é e do que os outros são, a pessoa que usa sua inteligência para receber a realidade, sabe que não teria nascido e sobrevivido sem o amparo e a ajuda de muitos. Existe, portanto, uma solidariedade natural, que decorre da fragilidade da pessoa humana e que deve ser completada com a solidariedade e construtiva com a força da justiça.

O debate acerca das violações dos direitos humanos compreende as dimensões de

\footnotetext{
${ }^{3}$ IPEA. Políticas Públicas. Acompanhamento e análise, 07/08/03. Instituto Cidadania. Disponível em: www.ipea.gov.br/. Acesso em: 18 nov. 2014.

${ }^{4}$ Declaração Universal dos Direitos Humanos artigo $1^{\circ}$, Santarém: Diocese de Santarém, 2003, p.2. Ver também: Violação dos Direitos Humanos: Sollicitudo Rei Socialis, 15,26,33; Panorâmica dos Direitos Fundamentais: Pacem in Terris, 143 a 144, II a 34; 75 a 79; Gaudium et Spes, 27, 79, 29, 60, 52, 75, 71, 67, 68, 65, 69, 59; Puebla, 3890 a 3893; Redemptor Hominis, 17; Sollicitudo Rei Socialis, 26, 33 a 34; Direitos Humanos como Exigência Evangé6ca; Puebla: Discurso de Abertura; Instrução sobre a Liberdade e a Libertação Cristãs, n.65.
} 
reparação, proteção e promoção dos DHESCA - Direitos Humanos Econômicos, Sociais, Culturais e Ambientais. Em 2009, o PAD-Processo de Articulação e Diálogo publicou o estudo de caso Brasil com o título: O impacto dos grandes projetos e a violação dos DHESCA $^{5}$. Este relatório mostra como o Brasil ainda está permanentemente violando os direitos individuais, sociais/coletivos e ambientais dos povos indígenas, afros descendentes e trabalhadores e trabalhadoras na Amazônia e no Brasil. Isso implica o marco na discussão dos defensores de direitos humanos que se dá a partir da ação concreta e cotidiana pela efetivação dos direitos, estabelecendo uma correlação imediata entre a luta destes defensores e a repressão contra os mesmos, buscando inibir a sua atuação (SAUER, 2005, p. 51-66).

O Brasil com o Movimento Nacional dos Direitos Humanos se fortalece pós ditadura militar, mostrando sua força na época da luta pela Constituição de 1988. Depois a Conferência de Viena em 1993 e a primeira Conferência de Direitos Humanos no Brasil em 1996. Esta luta resultou na criação do PNDH I- Programa Nacional dos Direitos Humanos pelo Decreto presidencial n. 1904 em 1996. O processo de elaboração de um programa Nacional foi se consolidando a ponto de chegarmos ao PNDH II e a criação do novo Decreto presidencial 4229 de 2002. No entanto, nos interessa nessa reflexão o fato de que existe o Programa Nacional de Direitos Humanos do PNDH III que foi publicado pelo Decreto n. 7.037 de 21 de dezembro de 2009 e atualizado pelo Decreto n. 7.177 de 12 de maio de 2010 . Neste sentido o documento final do PNDH III apresenta um longo programa e que podemos resumir em 4 eixos orientadores dos Direitos Humanos com seus desafios: Interação democrática entre Estado e sociedade civil; Desenvolvimento e Direitos Humanos; universalizar direitos em um contexto de desigualdades; e Direito à Memória e à Verdade.

A Entidade Terra de Direitos, através de seus representantes e assessores, Ciconello, Pivatto e Frigo dizem que:

\footnotetext{
${ }^{5}$ Ver sobre DHESCA os estudos de caso PAD Brasil (Processo de Articulação e Diálogo). Publicação do PAD. O impacto dos grandes projetos e a violação dos DHESCA. Rio de Janeiro, 2009. Ver também sobre o DHESCA BRASIL. Disponível em: www.dhescbrasil.org.br/. Acesso em: 21 nov 2014. Sobre a dignidade da Pessoa humana ver o Livro de Márcia R. Bertoldi e Karyna B. Sposatocom o título: Direitos Humanos:entre a utopia e a contemporaneidade. Belo Horizonte: Forum, 2001.pp. 131-153 com a reflexão sobre a Interculturalidade e o diálogo onde respeitam, protegem e promovem os Direitos Humanos. Também de Ingo W. Salet e Jayne Eingartnes, o capítulocom o título: Algumas notas sobre a relação entre Dignidade (da pessoa) humana, Os Direitos Humanos e fundamentais e o ensino jurídico.
} 
O principal desafio para a implementação do PNDH é transformá-lo em uma política de Estado, não de um governo, ou mesmo da Secretaria Especial de Direitos Humanos. Isso significa que ele deve ser um instrumento de referência para a formulação de programas e ações tanto para o poder executivo, mas também para o poder legislativo e judiciário. Uma das principais dificuldades de todo o processo foi o de envolver representantes do Poder Judiciário na discussão e também no compromisso de implementação do Programa. É notório que dentro do próprio governo federal há contradições que emergiram neste processo, como a recusa do Ministério da Defesa em subscrever o PNDH, retardando ainda mais seu lançamento público, por opor-se à criação da Comissão de Memória e Justiça, aprovada durante a Conferência e subscrita pela SEDH e a quase totalidade dos Ministérios (CIONELLO; PIVATTO; FRIGO, 2002).

O PNDH III reconhece nos direitos presentes na sociedade hoje, principalmente na referência aos direitos coletivos e ao meio ambiente equilibrado e sustentável, como consta no artigo 225 da Constituição Federal de 1988, garantindo vida digna para as presentes e futuras gerações. Como efetivar esses direitos e construir um projeto de sociedade que contemple todas as dimensões e todos os povos na sociedade pluricultural.

Diante disso, vamos pegar como exemplo, a necessidade de proteção de vida dos defensores e defensoras dos direitos humanos da Amazônia brasileira. O Pará apresenta o maior índice de assassinatos ligados às disputas de terra. Entre 1985 a 2001, quase 40\%, das 1237 mortes de trabalhadores rurais no Brasil aconteceram no Pará. É ainda o estado campeão de desmatamento ilegal, exploração de madeira, grilagem de terras, trabalho escravo e palco de escandalosas denúncias de abuso aos Direitos Humanos ${ }^{6}$. No entanto, existe uma resistência cotidiana dos povos indígenas, ribeirinhos, quilombolas, extrativistas e agricultores familiares contra as injustiças, desigualdades e violência.

Esses grupos étnicos lutam na construção de projetos baseados na partilha, na sustentabilidade socioambiental e na organização comunitária, garantindo a dança da vida com princípios éticos, voltados para a coletividade, evitando o egocentrismo, separatismo e o individualismo. Nesse sentido, os defensores dos direitos humanos apontam para os processos de resistência e defesa de direitos sociais, econômicos, culturais e religiosos da população Amazônica. (ALDUNATE, 1991, p. 91-136).

\footnotetext{
${ }^{6}$ Relatório do Greenpeace "Pará: Estado de Conflito", lançado em outubro de 2003: htt : www. reen eace.or .br amazonia di ara estadodeconflito. df. Ver também. Sérgio Sauer. Violação dos Direitos Humanos na Amazônia: conflito e violênda na fronteira paraense. Goiânia: CPT, 2005. E CPT- Comissão Pastoral da Terra: Conflitos no Campo_ Brasil. Goiânia: CPT, 2005
} 
Diante de tantas ameaças de morte e assassinatos no campo e na cidade no Brasil e especialmente no estado do Pará, a X Conferência Nacional de Direitos Humanos, reunido em Brasília em junho de 2006, lançou uma carta compromisso dos Defensores e Defensoras de Direitos Humanos:

\begin{abstract}
Reunidos na X Conferência Nacional de Direitos Humanos, nós defensoras e defensores de direitos humanos, que militamos e lutamos todos os dias em nossas entidades, movimentos sociais e instituições públicas para que sejam respeitados, protegidos, promovidos e garantidos os direitos humanos de todos os povos, mulheres e homens, crianças, jovens e idosos, migrantes, trabalhadores e trabalhadoras rurais, urbanos e domésticos, pessoas com deficiência; nós que lutamos sem parar para que todas as pessoas tenham liberdade para professar sua fé religiosa sem restrição, para que tenham a liberdade de orientação sexual sem qualquer constrangimento; nós que lutamos para que educação de qualidade, saúde acessível e de qualidade, trabalho e renda, dignidade e respeito sejam garantidos a todos, homens e mulheres sem qualquer discriminação e exceção; nós que exigimos a regularização imediata das terras quilombolas e o reconhecimento dos direitos indígenas [..]. A valorização e o reconhecimento do papel dos defensores e defensoras dos direitos humanos é condição essencial para o avanço da democracia e da cidadania no Brasil ${ }^{7}$.
\end{abstract}

Assim, o PNDH III reconhece que muito se fez, mas que precisa avançar nas estratégias da ação da cidadania contra a miséria a favor da vida. Ninguém deve viver na miséria, pois todos têm direito à vida digna. Segundo João Batista Herkenhoff, há duas dimensões de violação aos direitos humanos na questão da miséria, pois:

\begin{abstract}
A situação da miséria fabrica ingredientes que favorecem as violações pessoais. Por outro, lado, essa situação de miséria e, por si só, a mais grave violação dos direitos Humanos, porque é uma violação coletiva. A miséria deste imenso mundo dos países pobres advém, em grande parte, de relações econômicas internacionais injustas (HERKENHOFF, 2002, p. 64).
\end{abstract}

Este é o desafio da sociedade como um todo. Superar as desigualdades da ordem econômica, política e social com uma política e planejamento do Estado na defesa dos Direitos, garantindo a efetivação dos Direitos Humanos como um projeto de sociedade.

\title{
5. OS CAMINHOS DE POTENCIALIZAÇÃO DOS DIREITOS HUMANOS E DESENVOLVIMENTO SOCIOAMBIENTAL
}

\footnotetext{
${ }^{7}$ PLENÁRIO da X Conferência Nacional de Direitos Humanos. Auditório Nereu Ramos, Câmara dos Deputados, Brasil, 2 de junho de 2006.
} 
As reflexões sobre a economia política e a promoção da paz para os povos, foram compiladas por Catherine Mulholland, do Conselho Mundial das Igrejas, que contraponto a um modelo capitalista excludente, propõe uma cultura de paz, superando as violências. Não basta lamentar a situação desfavorável do povo, diante do atual modelo de sociedade apresentada pelo neoliberalismo. Faz-se necessário uma postura de enfrentamento, mas também de construção de valores humanos, tais como: cidadania, fraternidade, participação, justiça, honestidade, solidariedade e a paz. Muitos são os caminhos que se abrem para que os direitos dos seres humanos sejam efetivados, dentre eles, alguns serão aprofundados a seguir.

\subsection{Cidadania e Fraternidade}

Um indivíduo, reconhecendo-se como um membro de seu país e sendo por este reconhecido com o mesmo status, é automaticamente alçado à condição de cidadão, pois passa a ter à sua disposição uma série de canais para participação, controle e influência das instituições político-sociais voltadas para o todo, interagindo com a comunidade onde reside habitualmente. Segundo Rodrigo Cintra, professor de Ética das Relações Internacionais no UNIBERO - Centro Universitário Ibero-Americano, afirma que:

Cidadania, mesmo sendo um conceito muito vago e sem substância,
transformou-se numa das bandeiras de luta mais comuns da
atualidade. Seu poder interno de legitimação é tão grande que seu
simples invocar parece tentar justificar todo um conjunto de
objetivos e utopias. A maior confusão que envolve o uso do
complexo conceito que é a cidadania é aquela entre cidadania e
dignidade humana. Ainda que ambas as ideias tenham uma forte
correlação entre si, a dignidade humana está ligada ao indivíduo ao
passo que a cidadania ao todo social. Um conjunto de ações
voltadas diretamente para as melhorias de condições de vida do
indivíduo e seu meio (CONIC, 2005).

Plínio de Arruda Sampaio na mesma direção, afirma que cidadania "é a participação como indivíduo ou como um grupo organizado nas mais variadas áreas de atuação na sociedade, na esfera pública. Então cidadania é sinônimo de participação, ou seja, de não omissão, indiferença em relação ao exercício do poder" (SAMPAIO, 2006) ${ }^{8}$. No Brasil, até 1888, se praticava a escravidão - embora, hoje, ainda se registre a existência do trabalho escravo em muitas regiões do país e, nessa época, o voto era privilégio de alguns. Os direitos

\footnotetext{
${ }^{8}$ Ver sobre o tema da cidadania o livro: A Revolução da Cidadania. Autor: Dirceu Galdino Cardin. Florianópolis: Editora OAB, 2006.
} 
das mulheres e dos trabalhadores são conquistas recentes.

Atualmente a fraternidade está sendo redescoberta como verdadeira categoria jurídica, inclusive no Direito Internacional. O conceito de fraternidade poderia se constituir em importante elemento para a compreensão dos problemas em cada país, possibilitando uma mudança radical nas relações internacionais. Por isso, afirma Cury:

Um campo no qual a ação da fraternidade aparece evidente é no reconhecimento dos direitos humanos em âmbito internacional, com um apelo aos Estados de respeitá-los, protegê-los e realizá-los, sem nenhuma forma de discriminação. O próprio ordenamento internacional é interpretado através dos direitos humanos. É nessa perspectiva também que estão definidas as estratégias para a cooperação entre os países, sobre o fundamento da dignidade humana e os valores a ela inerentes. Entre esses valores se coloca a fraternidade, invocada pela Declaração Universal dos Direitos Humanos do Homem de 1948, seja no seu Preâmbulo, onde se reconhece a "dignidade inerente a todos os membros da família humana", como também no seu artigo $1^{\circ}$, o qual exige dos titulares de direitos "agir uns com os outros com espírito de fraternidade (CURY, 2006, p. 22-23).

A revolução da cidadania percorre o caminho para alcançar a cidadania plena. Daí, o problema do desaparecimento dos valores humanos como cultura, como afirma Batista Mondin:

No âmbito da cultura, lugar privilegiado cabe aos valores; assim, podemos dizer que se a cultura é a alma da sociedade, os valores são, por sua vez, a alma da cultura. Por esse motivo, a grandeza de uma cultura é sempre proporcional à grandeza de seus valores. Uma cultura cresce, progride e prospera na medida em que cresce, progride e prospera a sua assimilação dos valores fundamentais; e uma cultura entra em crise e se esfacela quando seus valores espirituais entram em crise e ficam esquecidos (MONDIN, 1997, p. 249).

Os princípios e valores se asseguram nos Direitos Humanos como "valores ínsitos à pessoa humana, indispensáveis ao seu desenvolvimento em sua tripla dimensão bio-psíquicaespiritual, não necessariamente positivados pelas Cartas Constitucionais. São conteúdo ou materialidade dos assim chamados direitos fundamentais, que dão a formalização nas ordens jurídicas internas a tais conteúdos jurídicos" (FERREIRA, 2006, p. 122) ${ }^{9}$.

A sociedade democrática se fortalece nas relações sociais de cidadania e participação. Infelizmente o Brasil é um país de desigualdades gritantes entre ricos e pobres. Mas também entre privilégios e carências como Marilena Chauí, diz na necessidade de alcançar a

\footnotetext{
9 Ver o artigo de EDUCAÇÃO EM DIREITOS HUMANOS COMO FORMAÇÃO DA CIDADANIA CULTURAL. pp. 123-144. In. BROCHADO, Mariá; ABERU, Décio; FREITAS, Natália. Educação em Direitos Humanos, uma contribuição mineira. Uma Coletânea de artigos elaborada pelo Projeto Integrando Ações de Educação em Direitos Humanos em Minas Gerais: uma parceria entre FMDH e UFMG. Órgão Fomentador: SEDH-Governo Federal. Disponível em:

http://www.direito.ufmg.br/edhmg/livro_eletronico/livro_eletronico.pdf.Acesso em; 22 nov. 2014.
} 
verdadeira cidadania na luta pelos Direitos universais da pessoa humana. Ele afirma:

Dizemos (...) que uma sociedade é democrática (...) quando institui direitos e que essa instituição é uma criação social, de tal maneira que a atividade democrática realiza-se como luta social e, politicamente, como um contra poder social que determina, dirige, controla, limita e modifica a ação estatal e o poder dos governantes. Fundada na noção de direitos, a democracia está apta a diferenciá-los de privilégios e carências.

Um privilégio é, por definição, algo particular que não pode generalizar-se nem universalizar-se sem deixar de ser privilégio. Uma carência é uma falta também particular ou específica que desemboca em uma demanda também particular ou específica, não conseguindo generalizar-se ou nem universalizar-se[...]. Em outras palavras, privilégios e carências determinam a desigualdade econômica, social e política, contrariando o princípio democrático da igualdade, de sorte que a passagem das carências dispersas em interesses comuns e desses aos direitos é a luta pela igualdade. (CHAUI, 2005, p. 23-30)

Na sua filosofia Chauí, acredita que o novo sujeito social, se constrói no cotidiano com seus valores e cultura cidadã, superando os conflitos para alcançar a justiça. João Batista M. Pinto e Alexandre Costa, apresentam os direitos humanos na perspectiva que:

Indicamos aspectos que permitem analisar os direitos humanos, não sob o prisma institucional, mas sob uma dimensão ampla constituída pela própria sociedade em seu processo sócio-histórico. A partir dessa referência, e considerando que os direitos humanos passaram a ser uma referência central para as sociedades, enquanto as ideologias políticas tradicionais não conseguem superar suas contradições fundamentais, analisamos os direitos humanos como um projeto de sociedade emancipador e mais adequado à realidade contemporânea (PINTO; COSTA, 2013).

São caminhos que potencializam o processo permanente e insistente de luta pela implementação dos Direitos Humanos na perspectiva ambiental.

\subsection{Desenvolvimento Socioambiental}

Há nesse sentido, uma inter-relação íntima entre as injustiças sociais e as injustiças ambientais, pois os modelos atuais de produção e de consumo são as principais causas da degradação ambiental. Segundo pesquisas, aproximadamente, um bilhão de pessoas adoece e dois milhões acabam por morrer devido ao consumo de água poluída. E concentração da terra nas mãos de poucos, deixando milhões de trabalhadores sem terra. Escravizamos a terra e exploramos a natureza desordenadamente. Mas os povos indígenas resistem e gritam em defesa da mãe terra, como Djiniyini Goudarra faz:

A Terra é a minha mãe. Tal como uma mãe humana, ela dá-nos proteção, prazer e toma conta das nossas necessidades econômicas sociais e religiosas. Nós temos relações humanas com a terra: de mãe, de irmã, de filho. Quando nos tiram a terra ou quando a destroem, nós sentimo-nos feridos, porque nós pertencemos à terra $\mathrm{e}$ 
fazemos parte dela (GOURARRA, 1997).

O problema do desequilíbrio ambiental e do aquecimento global vem exatamente da forma como o ser humano vem utilizando a terra, desde a revolução industrial e a ganância do neoliberalismo. Por isso, a questão da sustentabilidade vai se tornando o tema principal, diante das questões mundiais de mudanças climáticas. Estes estudos vem sendo feito entre outras entidades e cientistas pelo IPCC - Intergovernmental Panel on Climate Change ${ }^{10}$. O Conselho Mundial de Igrejas Cristãs assume o compromisso com a Amazônia, afirmado:

A Amazônia total, cuja maior área fica no Brasil, mas compreendendo também parte do território venezuelano, colombiano e peruano, é considerada por nós como patrimônio da humanidade. A posse dessa imensa área, pelos países mencionados, é meramente circunstancial. É nosso dever defender, prevenir, impedir, lutar, insistir, convencer, enfim, esgotar todos os recursos que, devida ou indevidamente, redundem na defesa, na segurança, na preservação desse imenso território e dos seres humanos que o habitam e que são patrimônio da humanidade, e não patrimônio dos países cujos territórios pretensamente dizem lhes pertencer (LUCENA, 2006) ${ }^{11}$.

Amazônia impõe a toda sociedade brasileira um grande desafio no sentido de evitar que tenha o mesmo destino de outras regiões tropicais, especialmente quanto a destruição florestal e pobreza social. O texto base da Campanha da Fraternidade de 2011, da CNBB, nos faz refletir sobre a necessidade de olhar para a realidade social e ambiental e indicam um "tipo de desenvolvimento que nos permite viver nos limites suportáveis para a Terra, que são a disponibilidade de recursos naturais e os limites de absorção de resíduos e poluição, mas também o tipo de desenvolvimento que torne possível a redução da pobreza"(CF 2011, n. 81). Se faz necessário, rever os conceitos de desenvolvimento sustentável. Por isso, devemos ter a sensatez para se eliminar os excessos de produção e consumo e buscar a equidade no uso dos bens. Neste sentido, Mahatma Gandhi pronunciou uma frase, cuja memória é oportuna: “o

${ }^{10}$ O IPCC- Intergovernmental Panel on Climate Change - Traduzindo: Painel Intergovernamental sobre Mudanças Climáticas - foi co-fundado em 1988 pelo Programa Ambiental das Nações Unidas e pela Organização Meteorológica Mundial. Sua missão: avaliar se o clima da Terra está mudando efetivamente. Integram este comitê cerca de 2800 pesquisadores de vários países e de diferentes disciplinas acadêmicas. O grupo elabora seus relatórios a partir de fontes fidedignas, aceitas pela comunidade científica internacional, e as avalia com rigor. O painel publicou quatro relatórios sobre mudança climática, em 1990, 1995, 2001 e 2007. Juntamente com esses documentos, o IPCC esboça os principais temas dos relatórios e publica um Resumo para Tomadores de Decisão. Disponível em: www.ipcc.ch. Acesso em: 18 nov. 2014.

11 Ver também em: JORNAL: O LIBERAL dia 14 de Junho de 2006. Folha Oeste do Pará. E também a GUERRA DA SOJA - Globo.com - 13/06/06 Os repórteres do Fantástico mostraram um território marcado por conflitos: www.valeverde.org.br/html/clipp2.php?id=6037\&categoria. Acesso em: 13 jun. 2006. 
mundo tem recursos suficientes para atender às necessidades de todos, mas não a ambição de todos" (CF 2011, n. 85).

Segundo José Afonso da Silva, se faz necessário ter uma postura de abertura ao projeto da defesa dos direitos humanos e ao meio ambiente. Ele afirma que:

O problema da tutela jurídica do meio ambiente manifesta-se a partir do momento em que sua degradação passa a ameaçar não só o bemestar, mas a qualidade da vida humana, se não a própria sobrevivência do ser humano [...] O que é importante é que se tenha consciência de que o direito à vida, como matriz de todos os direitos fundamentais do homem, é que há de orientar todas as formas de atuação no campo de tutela do meio ambiente. Cumpre compreender que ele é um fator preponderante, que há de estar acima de quaisquer outras considerações como as de desenvolvimento, como as de respeito ao direito de propriedade e como as de iniciativa privada. (SILVA, 2000, p.28, 67)

Hoje, podemos observar a exploração da Amazônia, através da madeira, da pecuária, abrindo espaço para a mono cultura da soja ${ }^{12}$. Esta nova fronteira agrícola da soja vem se expandindo desde o sul do país e Mato Grosso. Agora com os portos em Santarém do Pará com a Cargill e outras empresas que se organizam para se instalar também em Itaituba, no rio Tapajós, transportando a soja e milho pela Rodovia BR 163 - Cuiabá- Santarém.

Os povos da América e principalmente da Amazônia, buscaram sempre se libertar da opressão, geraram símbolos de resistência e de aguda profecia, que foram configurando a experiência concreta, sobretudo em termos de busca universal de um mundo melhor. Faz-se urgente assim, descobrir, apreciar e transmitir as crenças, os valores, as possibilidades e as utopias do "outro mundo possível", tão debatidos nos FSM- Fórum Social Mundial ${ }^{13}$, pois é possível enriquecer a luta e sonhos dos líderes dos movimentos sociais que se tornaram referência na conquista de espaço e reconhecimento dos direitos humanos na sociedade.

\subsection{Movimentos Sociais e os Mártires da Amazônia}

Um dos principais problemas juntamente com a questão ambiental na região amazônica é a grilagem de terras, especialmente através da falsificação de documentos que

\footnotetext{
${ }^{12}$ Ver sobre o tema da Soja na Amazônia, documento na FASE e CPT, a Palestra proferida por Sérgio Scillesinger: O Grão que cresceu demais. Seminário com entidades do Baixo Amazonas. Santarém 2005. Ver também DVD do Greenpeace: o grão que cresceu demais. Disponível em: www.youtube.com. acesso em: 14 nov. 2014.

${ }^{13}$ O FSM é um espaço que os movimentos sociais vendo sendo construído desde 2001 na primeira edição de pensar que um outro mundo é possível na defesa dos direitos humanos e meio ambiente. Disponível em: www.forumsocialmundial.org.br/home.asp. Acesso em: 18 nov 2014.
} 
busca privatizar as terras públicas. Diante dessa realidade, nos diferentes estados da região amazônica, realizam-se cursos, encontros, debates, com o intuito de conscientizar a população, especialmente os trabalhadores rurais, para ampliar a resistência e defesa dos direitos humanos. A luta pela preservação da Amazônia transformou-se em uma questão mundial porque sua destruição poderá ter um impacto sobre todo o planeta, isto porque o desequilíbrio ambiental poderá provocar uma tragédia sem precedentes na história humana. A necessidade de garantir a vida em todos os sentidos têm impulsionado o surgimento de movimentos sociais e eclesiais em defesa da Amazônia. Movimentos que buscam oferecer resistência e propor alternativas aos ataques sistêmicos do poder político e econômico ao ecossistema e à população amazônica. São problemas que exigem uma luta constante no sentido de promover a Justiça e a Paz.

O Papa Francisco no dia 31 de outubro de 2014, fez um discurso aos Movimentos Populares, reunidos em Roma no encontro Internacional dos Movimentos Populares. Ele ressaltou entre muitos aspectos, a importância dos líderes mundiais em defesa da justiça e dignidade da vida humana. A palavra solidariedade com os pobres foi bem destaca, pois os pobres querem ser protagonistas de um mundo novo. Ele anima a todos dizendo:

\begin{abstract}
Os pobres não se contentam com promessas ilusórias, desculpas ou pretextos. Também não estão esperando de braços cruzados a ajuda de ONGs, planos assistenciais ou soluções que nunca chegam ou, se chegam, chegam de maneira que vão em uma direção ou de anestesiar ou de domesticar. Isso é meio perigoso. Vocês sentem que os pobres já não esperam e querem ser protagonistas, se organizam, estudam, trabalham, reivindicam e, sobretudo, praticam essa solidariedade tão especial que existe entre os que sofrem, entre os pobres, e que a nossa civilização parece ter esquecido ou, ao menos, tem muita vontade de esquecer (PAPA FRANCISCO, 2014).
\end{abstract}

No seu discurso o Papa Francisco deixa claro a opção da Igreja de estar a serviço dos pobres e de suas organizações, pois o problema da fome, falta de terra, teto e trabalho para os pobres causam dor e injustiça. E a necessidade de ter paz e defesa da ecologia. Essa manifestação do seu pensamento em defesa dos direitos dos trabalhadores e da ecologia fica claro no seu pronunciamento, quando afirma:

Todo trabalhador, esteja ou não no sistema formal do trabalho assalariado, tem direito a uma remuneração digna, à segurança social e a uma cobertura de aposentadoria. Aqui há papeleiros, recicladores, vendedores ambulantes, costureiros, artesãos, pescadores, camponeses, construtores, mineiros, operários de empresas recuperadas, todos os tipos de cooperativados e trabalhadores de ofícios populares que estão excluídos dos direitos trabalhistas, aos quais é negada a possibilidade de se sindicalizar, que não têm uma renda adequada e estável. Hoje, quero unir a minha voz à sua $\mathrm{e}$ acompanhá-los na sua luta. 
Neste encontro, também falaram da Paz e da Ecologia. É lógico: não pode haver terra, não pode haver teto, não pode haver trabalho se não temos paz e se destruímos o planeta. São temas tão importantes que os Povos e suas organizações de base não podem deixar de debater. Não podem deixar só nas mãos dos dirigentes políticos. Todos os povos da terra, todos os homens e mulheres de boa vontade têm que levantar a voz em defesa desses dois dons preciosos: a paz e a natureza. A irmã mãe Terra, como chamava São Francisco de Assis (PAPA FRANCISCO, 2014).

O discurso do Papa Francisco reforça a luta já existentes dos movimentos populares dos trabalhadores, povos indígenas, quilombolas, ribeirinhos e migrantes da Amazônia. Assim, poderemos associar este tema da defesa da dignidade humana e respeito à natureza com as inúmeras organizações. Por isso na Amazônia, os povos da floresta reivindicam o direito da floresta em pé com sua forma de extrativismo. Daí surgiu as Unidades de Conservação, também chamadas de Reservas extrativistas ${ }^{14}$. A proposta de criação das Reservas Extrativistas e o desenvolvimento sustentável na Amazônia, nasceu como forma de resistência dos seringueiros do Acre ao processo de expansão capitalista naquele estado, tendo como pano de fundo a intrínseca e injusta estrutura fundiária ali predominante. Do confronto entre a estrutura chegante e a tradicional, nasceu uma forma de resistência inédita entre os trabalhadores rurais brasileiros: o "empate", que significa impedir, empatar uma atividade, no caso, o desmatamento.

O martírio voltou a fazer parte da vida da Igreja e na sociedade pós-moderna. Se o Evangelho for vivido a sério, terá com consequência, o sangue derramado dos mártires. O Apóstolo Paulo já nas Primeiras Comunidades Cristãs, afirmava que existia poderes e principados, atuando neste mundo e na sua história, pois são contrários aos movimentos da Vida. Entre 1979 a 1988, foi de uma época de assassinatos de líderes dos Direitos Humanos, tais como: Santo Dias (SP), Margarida Alves (PB), Pe. Josimo Távares (MA), Pe. Ezequiel Ramin (RO), Ir. Adelaide Molinari (PA) e Chico Mendes (AC).

Destacamos aqui separadamente o Líder seringueiro Chico Mendes para dar verificarmos sua atuação em Defesa dos Direitos Humanos em sintonia com o direito à terra e ao meio ambiente. Assim, os seringueiros e suas famílias, assumiram desde 1979, o impedimento das derrubadas da floresta no Acre. Enfrentando mandados judiciais, o poderio do latifúndio e, não raramente, a polícia do estado, os seringueiros, com suas mulheres e

\footnotetext{
${ }^{14}$ Ver sobre as Reservas Extrativistas e o desenvolvimento sustentável na Amazônia o livro de ANDERSON, Anthony e et al. O destino da Floresta: reservas Extrativistas e o desenvolvimento sustentável na Amazônia. Rio de Janeiro: Relume Dumará, 1994.
} 
crianças, deslocam-se para as linhas de frente de uma derrubada e, pacificamente, tentam convencer os trabalhadores contratados para o serviço de desmatamento a abandonarem a área, deixando a mata de pé, porque dela dependem para viver. No início de 1987, após o I Encontro dos Povos da Floresta, liderado por Chico Mendes, os extrativistas conseguem convencer o Governo Federal e, através da Portaria do INCRA n. 627, de 30 de julho de 1987, no contexto de Reforma Agrária, cria-se a primeira reserva extrativista. Este resultado foi alcançado por Chico Mendes, depois de ter ido aos Estados Unidos, na ONU e no BIRD em 1987. Ele conseguiu bloquear os empréstimos financeiros para os fazendeiros e criar a primeira reserva extrativista em Xapuri. Foi assassinado em 22 de dezembro de 1988. Ele disse um dia: "Se minha morte servir para pôr fim a impunidade dos fazendeiros e latifundiários do Acre até que valia a pena. Mas a experiência nos ensina o contrário. Não é com grandes funerais que iremos salvar a Amazônia. Não quero flores no meu funeral, pois sei que elas serão arrancadas da floresta. Eu Quero Viver"15 Hoje são inúmeras Reservas Extrativistas, como é o caso da criação em 1998 da Reserva Extrativista Tapajós-Arapiuns, no município de Santarém, estado do Pará (MENEZES, 1994, 49-72).

Amazônia com características distintas de assumir a luta em defesa da terra, em 2001 com a chegada da empresa multinacional Cargill, em Santarém, Pará, atraindo os produtores de soja para a Amazônia, resultou em inúmeros conflitos, devido a grilagem de terras públicas. Por isso, surgiu a Frente em Defesa da Amazônia - FDA. Movimento fundado por cidadãos, cidadãs, lideranças dos movimentos sociais, das pastorais sociais da Igreja, dos movimentos estudantis (FDA, 2005, n. 1-2). Esta luta em defesa da terra e dos Direitos Humanos muitos foram assassinados como é o caso da Irmã Dorothy. Há mais de 30 anos vivia na região da Transamazônica e dedicou quase metade de sua vida para dar voz às comunidades rurais, defendendo o direito à terra e lutando por um modelo de desenvolvimento sem destruição da floresta. A frase que ela sempre repetia era "o fim da floresta é o fim de nossa vida". O GT A Grupo de Trabalho Amazônico e coordenação do FBOMS - Fórum Brasileiro de ONGs e Movimentos Sociais. Esse documento, assinado por Adilson Vieira e outros:

Do ponto de vista ambiental o assassinato da Irmã Dorothy poderia ser classificado como um impacto secundário da colonização

\footnotetext{
${ }^{15}$ Depoimento de Chico Mendes na ONU. Ver Vídeo da Verbo Filmes: Chico Mendes. São Paulo. 1990. 47 http://www.fboms.org.br/doc_dorothy.htm
} 
espontânea associado ao desmatamento total e agricultura de corte e queima, a exploração ilegal de madeira, a grilagem e invasão de terras, a violência e morte no campo, a omissão e a inoperância do Estado. Na verdade, são problemas históricos de origem socioeconômicos que se arrastam desde os primórdios da humanidade (VIEIRA, 2005) ${ }^{16}$.

Ficamos refletindo a situação da violência, a partir do assassinato da Irmã Dorothy, pois foi exatamente em 2005. Ano que a CBB, lançou a Campanha da Fraternidade Ecumênica com o tema: Solidariedade e Paz, sendo o lema: "Felizes os que Promovem a Paz" (Mt 5,9). Esta programação da CNBB já vinha desde o ano 2000, com a reflexão ecumênica sobre o novo milênio sem exclusões que refletia sobre "Dignidade humana e paz". Trata-se não somente de resgatar e defender a dignidade de todas as pessoas, mas de percorrer juntos o caminho da solidariedade para criar condições de paz ${ }^{17}$. Toda essa luta pela paz vem da programação feita pela ONU na questão da década para a cultura da paz. Segundo o Programa de Proteção dos Defensores e Defensoras dos Direitos Humanos, no relatório de 2006, 120 pessoas estavam ameaçadas no Pará. Entre eles: Frei Henri de Roziers, da CPT de Xinguara; Dom Erwin Kaulter, Bispo do Xingu; Padre Edilberto Sena da diocese de Santarém e Padre José Boeing, advogado da CPT e membro dos Missionários do Verbo Divino. Ameaças e assassinatos na Amazônia motivados especialmente pela "impunidade que mata e desmata". Mas a paz é possível, como Paulo Freire já nos direcionava o sentido da verdadeira paz com justiça social. Ele afirmava que: “A paz se cria, se constrói na e pela superação das realidades sociais perversas. A paz se cria, se constrói na construção incessante da Justiça Social. Por isso, não creio em nenhum esforço chamado de educação para a paz que, em lugar de desvelar o mundo das injustiças, o torna opaco e tenta miopizar suas vítimas"18. Seguimos anunciando a esperança de que uma sociedade justa e fraterna é possível.

Muitos são os projetos de busca de alternativas para superar as violências e construir uma cultura de paz. Na promoção da cidadania e na defesa da vida e dos direitos humanos, principalmente na região de Santarém no oeste do Pará, realizamos iniciativas democráticas

\footnotetext{
${ }^{16}$ Ver Documento que Adilson Vieira enviou ao Presidente Luiz Inácio Lula da Silva. FBOMS. Ver no site: www.portalverdeonline.com.br/oalrinasloDiniao/irmadorotv.htm

17 Ver texto base da Campanha da fraternidade ecumênica 2005. Disponível em: http://www.luteranos.com.br/conteudo/campanha-da-fraternidade-ecumenica-200 5-9-de-fevereiro. Acesso em: 22 nov. 2014.

${ }^{18}$ Ver sobre projeto educação para a paz in. Ana Maria Freire - Educação Para a Paz Segundo Paulo .... Disponível em: https://docs.google.com/document/d/1Q-I17BJ.../edit?hl=en. Acesso em: 22 nov 2014.
} 
na conciliação e mediação dos conflitos. Utilizamos a Justiça Restaurativa como fundamento para construir uma sociedade mais justa e fraterna. Condena-se o crime ou delito, mas restaura o ofendido/agredido e o ofensor/agressor. Mas para chegar a este processo de práticas restaurativas, se faz necessário um processo formativo dos líderes populares para agirem como mediadores nos conflitos socioambientais.

Na Amazônia, surgiu o Projeto de Formação de Agentes Comunitários de Justiça, Paz e Cidadania. Iniciativa da Comissão de Justiça e Paz da CNBB, Norte II, Pará e Amapá em 2002. Como a participação nesse projeto de líderes dos Movimentos Sociais com 100 h/aulas, coordenado pela Comissão de Justiça e Paz da Diocese de Santarém, Pará e da Comissão Verbita JUPIC - Justiça, Paz e Integridade da Criação na Amazônia, o projeto se ampliou para a formação de mediadores de conflitos, contribuindo para transformar os cidadãos como sujeitos atuantes na sociedade. O desafio consiste na efetivação Direitos Humanos e o respeito ao Meio Ambiente desde a perspectiva da justiça restaurativa.

\section{CONSIDERAÇÕES FINAIS}

Se por um lado existe a política Neoliberal, por outro, também existe a luta pela Globalização dos Direitos Humanos, que rompem barreiras e fronteiras, garantindo os direitos universais. É a luta contra a impunidade e pela aplicação das leis justas, que segundo a Constituição Federal de 1988, no artigo $5^{\circ}$ diz que todos "são iguais perante a lei". Sendo assim, realizar o resgate da Cidadania e Direitos Humanos passa pela valorização da dignidade da pessoa humana, que não é mais escravo, e sim livre, num estado democrático. Portanto, a luta pela proteção dos defensores e defensoras dos direitos humanos é essencial, pois eles e elas precisam continuar os trabalhos da construção de uma sociedade baseada nos valores da ética, da moral, da justiça e da paz, como dizia Gandhi: "Não existe caminho para a Paz. A paz é o Caminho". (CHOPRA, 2005). Os Direitos Humanos e a questão ambiental estão intimamente ligados pela ação humana que se articula com as bases da política pública de viabilidade econômica, equidade social e prudência ecológica na perspectiva dialética da sociedade em pleno desenvolvimento nas relações contraditórias e de interesses difusos.

Construir um projeto de sociedade baseado nos Direitos Humanos é o desafio para as dimensões políticas, socioeconômicas, ética, cultural e religiosa, pois o direito não privilégio, mas dignidade da pessoa humana na promoção d ajustiça social como compromisso político no âmbito nacional e internacional. Esta temática foi discutida no Seminário Nacional: “Os 
Direitos Humanos como projeto de sociedade", realizado nos dias 27 e 28 de agosto deste ano e organizado pelo Grupo de Pesquisa da Escola Superior Dom Helder Câmara sobre os Direitos Humanos e Meio Ambiente, coordenado pelo João Batista Moreira Pinto. Pensar o projeto emancipatório como efetivação e potencialização dos Direitos Humanos é abrir caminhos e perspectivas de uma nova sociedade com metodologia própria dos seus atores sociais. Os Direitos Humanos como projeto de sociedade é o caminho para a fraternidade e justiça social. 